\title{
Toll-like receptor activation by sino-nasal mucus in chronic rhinosinusitis*
}

\author{
Kristi Biswas ${ }^{1}$, Ana Chang², Michael Hoggard³, Fiona J. Radcliff4, Yannan \\ Jiang ${ }^{5}$, Michael W. Taylor ${ }^{3}$, Richard Darveau², Richard G. Douglas ${ }^{1}$ \\ Rhinology 55: 59-69, 2017 \\ https://doi.org/10.4193/Rhino16.201 \\ ' Department of Surgery, University of Auckland, New Zealand \\ *Received for publication: \\ ${ }^{2}$ School of Dentistry, University of Washington, Seattle, WA, USA \\ June 28, 2016 \\ ${ }^{3}$ School of Biological Sciences, University of Auckland, New Zealand \\ Accepted: September 14, 2016 \\ ${ }^{4}$ Department of Molecular Medicine and Pathology, University of Auckland, New Zealand \\ ${ }^{5}$ Department of Statistics, University of Auckland, New Zealand
}

\begin{abstract}
Background: The sino-nasal disease chronic rhinosinusitis (CRS) is primarily an inflammatory condition that manifests in several ways. However, the aetiology of this complex disease is poorly understood. The aim of this study was to explore the association between toll-like receptor (TLR) activation, host immune response and sino-nasal mucus in healthy and diseased patients.

Methods: The activation of TLR2/1 and TLR4 by sino-nasal mucus from 26 CRS patients and 10 healthy controls was measured. In addition, 7 inflammatory cytokines, bacterial community composition and bacterial abundance within the sino-nasal mucus were measured using molecular and diagnostic tools.
\end{abstract}

Results: TLR activity was observed in 9/36 samples, including 2 healthy controls. There was a strong, positive correlation between members of the Gammaproteobacteria (Haemophilus, Enterobacter, Pseudomonas) and TLR2/1 and TLR4 activity. Bacterial abundance and cytokine (tumour necrosis factor) abundance were also positively correlated with TLR activity.

Conclusions: These findings suggest that a small proportion (20-30\%) of individuals in each sub-group are more predisposed to TLR activity, which may be related to bacterial composition, diversity and abundance in the sinuses.

Key words: Human toll-like receptors, cytokines, sinusitis, microbiota, 16S ribosomal RNA

\section{Introduction}

Chronic rhinosinusitis (CRS) is fundamentally an inflammatory sino-nasal disease that persists for over 12 weeks, and occurs in $>5 \%$ of the general population ${ }^{(1,2)}$. CRS is generally classified into two broad categories based on phenotype: one with nasal polyps (CRSwNP) and one without (CRSsNP) ${ }^{(3,4)}$. However, the aetiology of CRS is poorly understood. Many of the current theories hold that infectious microbial agents and their products initiate inflammatory changes in the host mucosa ${ }^{(5)}$. Research from our own group has suggested that an imbalance (dysbiosis) in the bacterial community structure may be linked to this process ${ }^{(6)}$. Recently, there has been an increased focus on the interface between host epithelial cells and the environment in the sino-nasal cavity of CRS patients $(7,8)$.

The airway epithelium plays an important role in innate host defence ${ }^{(7,9)}$, as it is the first point of contact between the mucosa and external environment. Pathogens are recognised by transmembrane receptors such as toll-like receptors (TLR) that are usually expressed on macrophages, dendritic cells, endothelial and epithelial cells ${ }^{(10,11)}$. To date, 10 functional TLRs have been identified in humans, of which TLR2/1 and TLR4 play a prominent role in recognising components of Gram-positive bacteria (peptidoglycan and lipoteichoic acid) and Gramnegative bacteria (lipopolysaccharide (LPS)) ${ }^{(12)}$. The activation of these TLRs results in activation of the NF- $\kappa B$ pathway, which results in production and release of inflammatory cytokines that stimulate the host innate and adaptive immune responses. Although a number of studies have investigated TLRs in lower respiratory diseases, very few have focused on sino-nasal diseases. All 10 TLRs have been shown to be expressed in both 
healthy and CRS sino-nasal mucosa ${ }^{(10)}$, while mRNA expression of TLR2 and TLR4 is significantly greater in CRS cohorts compared with controls ${ }^{(13,14)}$. Recent work has begun to explore the possible nature of interactions between the host and its associated microbiota ${ }^{(15,16)}$. These previous studies have targeted specific groups of bacteria, which risks overlooking the role of other organisms in the community and their influences on host inflammatory responses. The existing literature reveals major discrepancies among different studies, which need to be addressed in the immediate future.

This study aims to investigate the complex interactions between the host and the microbial components associated with sinonasal mucus by analysing host inflammatory cytokines, bacterial community structure, and bacterial abundance in sino-nasal mucus of patients with CRSwNP, CRSsNP, CRS with cystic fibrosis (CF), and healthy controls. In addition, the activation of TLR2/1 and TLR4 receptors was measured in vitro using transfected human embryonic kidney (HEK) cells. The findings from this study provide novel insights into the role that bacterial diversity and/ or abundance play in influencing host inflammatory responses through TLRs in sino-nasal disease.

\section{Materials and methods}

Patients and sample collection

A total of 26 CRS patients were recruited for this study, of which 11 had nasal polyps (CRSwNP), 9 had no nasal polyps (CRSSNP) and 6 had cystic fibrosis (CRS/CF). In addition, 10 healthy control patients undergoing endoscopic sinus surgery for pituitary tumour resection were recruited. Clinical information for each patient is presented in Table 1. Written consent from the patients and ethical approval (NTX/08/12/126) from the New Zealand Health and Disability Ethics Committee was obtained for this study.

Nasal lavage samples were collected from the sino-nasal cavity of patients undergoing endoscopic sinus surgery by a single ORL surgeon (RGD). The mucus within the nasal cavity was gently sucked out into a sterile $10 \mathrm{~mL}$ Leukotrap ${ }^{\circledR}$ prior to surgical intervention. Samples were placed on ice and transported to the laboratory within $2 \mathrm{~h}$ of collection. A third of the volume of each sample was freeze-dried for $48 \mathrm{~h}$ before shipment to the University of Washington (Seattle) for further analysis. The remaining samples were handled and processed according to standard biological laboratory practices, and stored at $-20^{\circ} \mathrm{C}$ until further analysis.

\section{Genomic DNA extraction}

Collected mucus was thawed on ice and $200 \mu \mathrm{L}$ was pipetted into a sterile Lysing Matrix E tube (MP Biomedicals, Australia). A negative extraction control containing $200 \mu \mathrm{L}$ sterile water was carried out in parallel. Genomic DNA was extracted as described previously ${ }^{(6)}$. In brief, cells were ruptured using a Qiagen
TissueLyser II at $25 \mathrm{~m} / \mathrm{s}$ for $2 \times 40 \mathrm{~s}$. Following centrifugation the supernatant was transferred to an AllPrep DNA/RNA Isolation Kit (Qiagen) spin column. Genomic DNA was extracted following the manufacturer's instructions and eluted in $30 \mu \mathrm{L}$ of DNasefree water. The quality and quantity of genomic DNA were measured on a Nanodrop 3300 spectrometer and by using a Qubit ${ }^{\circledR}$ dsDNA HS (High Sensitivity) Assay kit (Life Technologies).

\section{S rRNA gene sequencing}

The V3-V4 region of the bacterial 16S rRNA gene was amplified from the genomic DNA using primers $341 \mathrm{~F}$ and $806 \mathrm{R}^{(17)}$. These primers have been recommended due to their broad taxonomic coverage ${ }^{(18)}$, and their suitability for investigating the sino-nasal microbiota was examined in silico using Probe Match in the Ribosomal Database Project ${ }^{(19)}$. For this study, $16 \mathrm{~S}$ rRNA gene amplicon sequencing was conducted using a dual-indexing (two-step PCR) approach with Nextera technology on the IIlumina MiSeq platform (2×300 bp paired-end reads). Primers contained overhanging Illumina adaptors, and were used in equimolar concentrations $(0.2 \mu \mathrm{M})$ in each $\mathrm{PCR}$ reaction. Other components of the reaction included genomic DNA template ( 10 ng), dNTPs (0.2 mM), HotStar PCR buffer (x1), $\mathrm{MgCl}_{2}(2 \mathrm{mM})$, $0.5 \mathrm{U}$ HotStar DNA polymerase (Qiagen) and PCR-certified water to a final volume of $25 \mu \mathrm{L}$. PCR amplification was performed in an Applied Biosystems Mastercycle gradient PCR machine with an initial denaturing step of $95^{\circ} \mathrm{C}$ for $15 \mathrm{~min}$, followed by 35 cycles of denaturation $\left(95^{\circ} \mathrm{C}\right.$ for $\left.30 \mathrm{~s}\right)$, annealing $\left(55^{\circ} \mathrm{C}\right.$ for $\left.30 \mathrm{~s}\right)$, and elongation $\left(70^{\circ} \mathrm{C}\right.$ for $\left.40 \mathrm{~s}\right)$, with a final elongation step at $70^{\circ} \mathrm{C}$ for $3 \mathrm{~min}$. Each sample was amplified in two separate reactions which were then pooled. Amplified products were purified using Agencourt AMPure XP beads (Beckman Coulter Inc.) as per the manufacturer's instructions, and eluted in $20 \mu \mathrm{L}$ of DNasefree water. Purified PCR products were quantified using the Qubit dsDNA HS Assay kit (Life Technologies), and qualitatively checked on Agilent High Sensitivity DNA chips (Agilent Technologies). The negative extraction control produced no amplifiable or quantifiable PCR product and thus could not be sequenced. Sequencing was performed by a commercial sequencing supplier (Macrogen, South Korea) on the Illumina MiSeq. Raw sequences have been uploaded to the NCBI Sequence Read Archive (BioProject number: PRJNA308506).

\section{Bioinformatic analysis of $16 \mathrm{~S}$ rRNA gene amplicon sequen-} ces

Raw sequences were analysed using a combination of USEARCH and QIIME software packages ${ }^{(20,21)}$. USEARCH was used to merge paired-end sequences, trim adaptors and primers, remove chimeras, and filter out sequences of $<200 \mathrm{bp}$. The remaining high-quality reads were assigned into operational taxonomic units (OTUs) based on 97\% 16S rRNA sequence similarity. Abundance data were re-incorporated into the dataset by mapping 
Table 1. Patient information for this study.

\begin{tabular}{|c|c|c|c|c|c|c|c|c|c|c|c|c|}
\hline Group & $\begin{array}{c}\text { Patient } \\
\text { No. }\end{array}$ & Revision & Age & $\begin{array}{l}\text { Euro- } \\
\text { pean }\end{array}$ & Sex & $\begin{array}{l}\text { PO* } \\
\text { score }\end{array}$ & Smoker & Asthma & $\begin{array}{l}\text { Aspirin } \\
\text { sensiti- } \\
\text { vity }\end{array}$ & $\begin{array}{l}\text { Anti- } \\
\text { biotic }\end{array}$ & $\begin{array}{l}\text { Pred- } \\
\text { nisone }\end{array}$ & LM† \\
\hline \multirow[t]{10}{*}{ Control } & 1 & $\mathrm{~N}$ & 46 & N & $\mathrm{F}$ & & $Y$ & $\mathrm{~N}$ & $\mathrm{~N}$ & N & $\mathrm{N}$ & \\
\hline & 2 & $\mathrm{~N}$ & 52 & Y & $\mathrm{F}$ & & Ex & $\mathrm{N}$ & $\mathrm{N}$ & $\mathrm{N}$ & $\mathrm{N}$ & \\
\hline & 3 & $\mathrm{~N}$ & 68 & $\mathrm{~N}$ & $\mathrm{~F}$ & & $\mathrm{~N}$ & $\mathrm{~N}$ & $\mathrm{~N}$ & $\mathrm{~N}$ & $\mathrm{~N}$ & \\
\hline & 4 & $\mathrm{~N}$ & 48 & $\mathrm{~N}$ & $\mathrm{~F}$ & & Ex & $\mathrm{N}$ & $\mathrm{N}$ & $\mathrm{N}$ & $\mathrm{N}$ & \\
\hline & 5 & $\mathrm{~N}$ & 84 & $\mathrm{~N}$ & $\mathrm{~F}$ & & $\mathrm{~N}$ & $\mathrm{~N}$ & $\mathrm{Y}$ & $\mathrm{N}$ & $\mathrm{N}$ & \\
\hline & 6 & $\mathrm{~N}$ & 69 & Y & $\mathrm{F}$ & & Ex & $\mathrm{N}$ & $\mathrm{N}$ & $\mathrm{N}$ & $\mathrm{N}$ & \\
\hline & 7 & $\mathrm{~N}$ & 61 & Y & $\mathrm{F}$ & & $\mathrm{N}$ & $\mathrm{N}$ & $\mathrm{N}$ & Y & $\mathrm{N}$ & \\
\hline & 8 & $\mathrm{~N}$ & 54 & Y & $\mathrm{F}$ & & $\mathrm{N}$ & $\mathrm{N}$ & $\mathrm{N}$ & $\mathrm{N}$ & $\mathrm{N}$ & \\
\hline & 9 & $\mathrm{~N}$ & 40 & Y & $\mathrm{F}$ & & Ex & $\mathrm{N}$ & $\mathrm{N}$ & $\mathrm{N}$ & $\mathrm{N}$ & \\
\hline & 10 & $\mathrm{~N}$ & 53 & Y & M & & Ex & $\mathrm{N}$ & $\mathrm{N}$ & $\mathrm{N}$ & $\mathrm{N}$ & \\
\hline \multirow[t]{9}{*}{ CRSsNP } & 1 & $\mathrm{~N}$ & 23 & Y & $\mathrm{F}$ & 15 & $\mathrm{~N}$ & $\mathrm{~N}$ & $\mathrm{~N}$ & $\mathrm{~N}$ & $\mathrm{~N}$ & 10 \\
\hline & 2 & Y & 67 & Y & $\mathrm{F}$ & 2 & Ex & $\mathrm{N}$ & $\mathrm{N}$ & $\mathrm{N}$ & $\mathrm{N}$ & 18 \\
\hline & 3 & $\mathrm{Y}$ & 53 & Y & M & 11 & Ex & $\mathrm{N}$ & $Y$ & $\mathrm{~N}$ & $\mathrm{~N}$ & 9 \\
\hline & 4 & $\mathrm{~N}$ & 33 & Y & $\mathrm{F}$ & 24 & $\mathrm{~N}$ & Y & $\mathrm{N}$ & $\mathrm{N}$ & $\mathrm{N}$ & 20 \\
\hline & 5 & $\mathrm{Y}$ & 58 & Y & M & 15 & $\mathrm{~N}$ & $\mathrm{~N}$ & $\mathrm{~N}$ & $\mathrm{~N}$ & $\mathrm{~N}$ & 16 \\
\hline & 6 & $\mathrm{~N}$ & 28 & $Y$ & M & 18 & $\mathrm{~N}$ & $\mathrm{~N}$ & $\mathrm{~N}$ & $\mathrm{~N}$ & $\mathrm{~N}$ & 9 \\
\hline & 7 & $\mathrm{Y}$ & 37 & Y & M & 5 & $\mathrm{~N}$ & $\mathrm{~N}$ & $\mathrm{~N}$ & $\mathrm{~N}$ & $\mathrm{~N}$ & 16 \\
\hline & 8 & $\mathrm{Y}$ & 41 & Y & $\mathrm{F}$ & 13 & $\mathrm{~N}$ & $Y$ & $\mathrm{~N}$ & $\mathrm{~N}$ & $\mathrm{Y}$ & 21 \\
\hline & 9 & $\mathrm{~N}$ & 19 & $Y$ & $\mathrm{~F}$ & 21 & $\mathrm{~N}$ & $\mathrm{Y}$ & $\mathrm{N}$ & $\mathrm{N}$ & $\mathrm{N}$ & 14 \\
\hline \multirow[t]{11}{*}{ CRSwNP } & 1 & $\mathrm{~N}$ & 39 & Y & M & 15 & $\mathrm{~N}$ & $Y$ & $\mathrm{~N}$ & $\mathrm{~N}$ & $\mathrm{~N}$ & 20 \\
\hline & 2 & $\mathrm{~N}$ & 18 & $\mathrm{~N}$ & M & 11 & $\mathrm{~N}$ & $Y$ & $\mathrm{~N}$ & $\mathrm{~N}$ & $\mathrm{~N}$ & 16 \\
\hline & 3 & $\mathrm{~N}$ & 37 & Y & M & 20 & $\mathrm{~N}$ & $Y$ & $\mathrm{~N}$ & $\mathrm{~N}$ & $\mathrm{~N}$ & 13 \\
\hline & 4 & $\mathrm{~N}$ & 37 & $\mathrm{~N}$ & M & 11 & $\mathrm{Y}$ & $\mathrm{N}$ & $\mathrm{N}$ & $\mathrm{N}$ & $\mathrm{N}$ & 20 \\
\hline & 5 & $\mathrm{Y}$ & 66 & $\mathrm{~N}$ & M & 18 & $\mathrm{Y}$ & $Y$ & $\mathrm{~N}$ & $\mathrm{~N}$ & $\mathrm{~N}$ & 23 \\
\hline & 6 & $\mathrm{~N}$ & 38 & Y & M & 22 & $\mathrm{Y}$ & $\mathrm{N}$ & $\mathrm{N}$ & $\mathrm{N}$ & $\mathrm{N}$ & 21 \\
\hline & 7 & $\mathrm{~N}$ & 31 & Y & $\mathrm{F}$ & 12 & $\mathrm{Y}$ & $Y$ & $\mathrm{~N}$ & $\mathrm{~N}$ & $\mathrm{~N}$ & 15 \\
\hline & 8 & $\mathrm{~N}$ & 43 & Y & M & 19 & $\mathrm{~N}$ & $Y$ & $\mathrm{~N}$ & $\mathrm{~N}$ & $\mathrm{~N}$ & 24 \\
\hline & 9 & Y & 25 & Y & $\mathrm{F}$ & 25 & $\mathrm{~N}$ & $Y$ & $\mathrm{~N}$ & $\mathrm{~N}$ & $\mathrm{~N}$ & 22 \\
\hline & 10 & Y & 71 & Y & $\mathrm{F}$ & 20 & Ex & Y & $\mathrm{N}$ & $\mathrm{N}$ & $\mathrm{N}$ & 23 \\
\hline & 11 & $\mathrm{~N}$ & 50 & $Y$ & $\mathrm{~F}$ & 18 & $\mathrm{~N}$ & $\mathrm{~N}$ & $\mathrm{~N}$ & $\mathrm{~N}$ & $\mathrm{~N}$ & 14 \\
\hline \multirow[t]{6}{*}{ CRS/CF } & 1 & Y & 21 & Y & M & 17 & $\mathrm{~N}$ & $\mathrm{~N}$ & $\mathrm{~N}$ & $\mathrm{~N}$ & $\mathrm{~N}$ & 21 \\
\hline & 2 & Y & 22 & Y & M & 7 & $\mathrm{~N}$ & $\mathrm{~N}$ & $\mathrm{~N}$ & $\mathrm{~N}$ & $\mathrm{~N}$ & 24 \\
\hline & 3 & $\mathrm{Y}$ & 37 & $Y$ & $\mathrm{~F}$ & 20 & $\mathrm{~N}$ & $\mathrm{~N}$ & $\mathrm{~N}$ & $\mathrm{Y}$ & $\mathrm{N}$ & 12 \\
\hline & 4 & $\mathrm{Y}$ & 50 & $\mathrm{~N}$ & $\mathrm{~F}$ & 17 & Ex & $Y$ & $\mathrm{~N}$ & $\mathrm{~N}$ & $\mathrm{~N}$ & 13 \\
\hline & 5 & $\mathrm{Y}$ & 31 & $\mathrm{Y}$ & $\mathrm{F}$ & 21 & $\mathrm{~N}$ & $\mathrm{~N}$ & $\mathrm{~N}$ & $\mathrm{Y}$ & $\mathrm{Y}$ & 19 \\
\hline & 6 & $Y$ & 32 & $Y$ & $\mathrm{~F}$ & 19 & $\mathrm{~N}$ & $\mathrm{~N}$ & $\mathrm{~N}$ & $Y$ & $Y$ & 16 \\
\hline
\end{tabular}

*PO: pre-operative symptom; † LM: Lund-Mackay; EX: ex-smoker; Y: yes; N: No 
the original sequence files with each unique OTU. The resulting dataset was converted into a biom table which could be further recognised by QIIME. Sequences were evenly subsampled to 3500 sequences per sample, and alpha diversity of the bacterial communities was estimated for each sample using the 'observed species' and Chao 1 richness metrics, and Shannon and Simpson diversity indices were used to measure richness and evenness. Rarefaction curves were built for each sample using the 'observed species' metric with a total of 100 permutations performed (Figure S1; online version).

Unique sequences from each representative OTU were taxonomically assigned against the SILVA 16 S rRNA gene database (version 119) using the uclust algorithm in QIIME. Abundance data were re-populated to the dataset using the biom table. A phylogenetic tree was constructed using FastTree 2.1.3 (22). Beta diversity measures (weighted and unweighted UniFrac, BrayCurtis dissimilarity) were calculated based on the constructed phylogenetic tree. Bray-Curtis results are shown in the MDS plots and are representative of the results from all three beta diversity measures (Figure S2; online version).

\section{Quantitative PCR to estimate bacterial abundance}

To investigate the impact of bacterial load on sino-nasal disease and TLR activation, the relative proportions of bacterial and human DNA in the extracts of each sample were estimated as described previously ${ }^{(6)}$. In brief, quantitative real-time PCR was employed to calculate the total number of 16S rRNA gene copies in the proportion of bacterial DNA present in the genomic DNA extract $(30 \mu \mathrm{L})$. For this purpose, primers bactin- $\mathrm{F}$ (nucleotide position, 393-413) and bactin- $\mathrm{R}(622-642){ }^{(23)}$ were used to target the human beta-actin (ACTB) gene, and primers $8 \mathrm{~F}$ and $341 \mathrm{R}^{(24,}$ ${ }^{25)}$ were used to target the bacterial 165 rRNA gene. Standards (including a 10-fold dilution series) for each gene of interest were prepared. Amplification efficiency of each primer pair was calculated based on the respective standard curve using the formula: $\mathrm{E}=10(-1 /$ slope $)-1 \times 100 \%$. Melting curve analysis was also performed to verify the specificity of the primer pairs, by using software 'dissociation curve' (Applied Biosystems). The reaction mix consisted of $7.5 \mu \mathrm{L}$ of $1 \times$ QuantiTect SYBR Green master mix (Qiagen) with HotStar Taq, $0.5 \mu \mathrm{L}$ of each primer (10 $\mu \mathrm{M}$ ), the respective genomic DNA template (10 ng for $16 \mathrm{~S}$ rRNA gene PCR; 1 ng for ACTB gene PCR) or prepared standard, and $\mathrm{PCR}$ grade water to a final volume of $15 \mu \mathrm{L}$. Thermal cycling conditions were as follows: $50^{\circ} \mathrm{C}$ for $2 \mathrm{~min}$, activation step at $95^{\circ} \mathrm{C}$ for $15 \mathrm{~min}$, followed by 40 cycles of denaturation $\left(95^{\circ} \mathrm{C}\right.$ for 15 $\mathrm{s})$, annealing $\left(60^{\circ} \mathrm{C}\right.$ for $\left.1 \mathrm{~min}\right)$, and elongation $\left(72^{\circ} \mathrm{C}\right.$ for $\left.15 \mathrm{~s}\right)$. All samples including the non-template control and dilution series of standards were run in triplicate. Results were analysed using the ABI Prism 7900HT sequence detection system (Version 2.4).

\section{Measurement of mucosal cytokines}

Mucus specimens from healthy, CRS and CF patients were tested for the presence of IL-2, IL-4, IL-6, IL-10, TNF, IFN- $\gamma$ and IL-17A by Cytometric Bead Array (CBA) using a Human Th1/Th2/Th17 Kit (BD Biosciences). CBA is an effective approach for measuring multiple cytokines in small sample volumes such as mucus ${ }^{(26,27)}$. Mucus samples were thawed on ice, centrifuged briefly to remove any particulate material, then supernatants were immediately transferred undiluted into CBA assay tubes and processed as per the manufacturer's instructions. CBA data were acquired on an LSR II with BD FACSDiva Software version 6.1.3 and analysed using FCAP Array ${ }^{\mathrm{TM}}$ version 1.0.1 (all BD Biosciences). Standard curves were produced using a 5-parameter logistic model with a fitting accuracy of $>99.9 \%$ for all cytokines. Values below the manufacturer's minimum detection limits for this assay are reported as zero.

\section{HEK293 cell TLR2/1 and TLR4 activation assays}

HEK293 cell TLR2/1 and TLR4 activation assays were performed as previously described ${ }^{(28)}$, with slight modifications. HEK293 cells were plated into 96-well plates at a density of $4 \times 10^{4}$ cells/ well and transfected the following day. Transfections were performed using calcium phosphate precipitation of plasmids encoding the firefly luciferase, Renilla luciferase, combined with plasmids bearing human mCD14, human TLR2 and human TLR1 (TLR2/1 assays), or combined with plasmids bearing human mCD14, human TLR4 and MD-2 (TLR4 assays). The cells were allowed to grow 20-24 h post-transfection and test wells were stimulated in triplicate for $4 \mathrm{~h}$ at $37^{\circ} \mathrm{C}$ and $5 \% \mathrm{CO}_{2}$ with the indicated concentrations of mucus in Dulbecco's modified Eagle's medium (DMEM) containing 10\% fetal bovine serum (FBS). Mucus samples were prepared as stock concentrations of $25 \mathrm{mg} /$ $\mathrm{mL}$ by adding ultrapure water to lyophilized patient samples, vortexing and sonicating for $5 \mathrm{~min}$ for maximum resuspension. Supernatants were collected following centrifugation at $4^{\circ} \mathrm{C}$ and stored at $-80^{\circ} \mathrm{C}$ until stimulation, whereby stock solutions were serially diluted in DMEM containing $10 \%$ FBS to the indicated concentrations ( $50 \mathrm{pg} / \mathrm{mL}$ and $5 \mathrm{pg} / \mathrm{mL}$ ). Following $4 \mathrm{~h}$ stimulations the reactions were terminated by washing the HEK293 cells with phosphate-buffered saline and lysing the cells with $50 \mu \mathrm{L}$ of passive lysis buffer (Promega). The luciferase activity of $10 \mu \mathrm{L}$ of each HEK293 cell lysate was measured using the Dual Luciferase Assay Reporter System (Promega). Positive controls using Escherichia coli LPS for TLR4 and synthetic triacylated lipoprotein (Pam3CSK4) for TLR2/1 were used. HEK cells transfected with reporter plasmids without either TLR4 or TLR2/1 were used as negative controls. Results are presented as increases in either TLR2/1 or TLR4 transfected cells compared with negative control cells. Data are expressed as fold increase of NF-KB-activity, which represents the ratio of NF-KB-dependent firefly luciferase activity to $\beta$-Actin promoter-dependent Renilla luciferase activity. 


\section{Statistical analysis}

Study data were entered into an Excel database, and imported to SAS version 9.4 (SAS Institute Inc. Cary NC) and R version 3.2.2 (R Foundation for Statistical Computing) for final analysis. All statistical tests were two-sided at a $5 \%$ significance level. No imputation was considered on the missing data. Demographic and clinical characteristics of all patients were summarised by patient cohorts. Continuous variables were presented as mean, standard deviation, median and range. Categorical variables were presented as frequencies and percentages. Differences between groups were first assessed on individual variables of interest using non-parametric tests with small sample sizes. More specifically, the Kruskal-Wallis test was used on continuous variables and the Fisher's exact test was used on categorical variables. When an overall significant difference was found between groups, post-hoc pairwise comparisons were conducted with Bonferroni adjustment for multiple comparisons. Spearman correlation coefficients were used to investigate the association between important variables, within healthy control and CRS groups. Adjusted relative risk and $95 \%$ confidence intervals were estimated.

\section{Results}

\section{Characteristics of the cohort}

Subjects chosen for this study were grouped into four categories based on sinus disease status, presence of nasal polyps, and comorbidity with cystic fibrosis (Table 1). Members of the control group were, overall, significantly older ( $p<0.01$, Dunn's test) than those in the CRS group. Interestingly, $90 \%$ of individuals in the control group were female, while males and females were more equally distributed in the CRS sub-groups. Another important clinical factor only observed in the CRS cohort was asthma.

There were no significant differences in the Lund-Mackay or preoperative symptom scores among the three CRS sub-groups.

\section{Bacterial diversity and abundance in nasal mucus}

A total of 660,881 high-quality $16 \mathrm{~S}$ rRNA gene sequence reads were used in this study after quality trimming. The number of reads for each sample varied from 8,838 to 31,309. The overall bacterial diversity (OTU richness) of the samples was low compared with that of many other human body sites (e.g. skin, intestine). The number of OTUs across all samples was 243. Bacterial richness and evenness were compared between patients with CRS without nasal polyps (CRSsNP), CRS with nasal polyps (CRSwNP), CRS with cystic fibrosis (CRS/CF), and healthy controls. All measures (Chao1, Observed OTUs, Shannon, Simpson) showed significant differences ( $p<0.05$, Kruskal-Wallis test) between the CRS/CF group and all others (Figure 1A-D). Interestingly, no significant differences in bacterial richness or evenness were observed among CRSsNP, CRSwNP, and healthy controls.
(A)
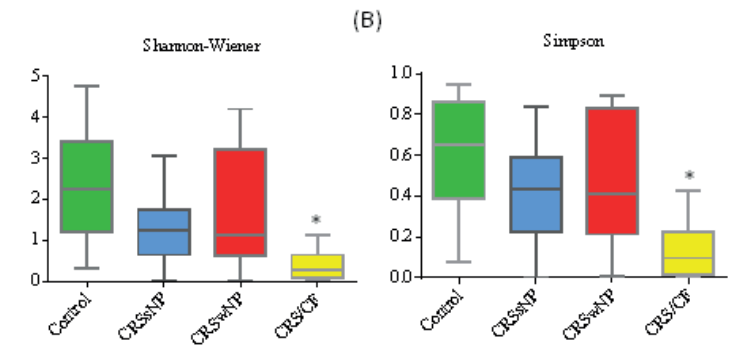

(C)
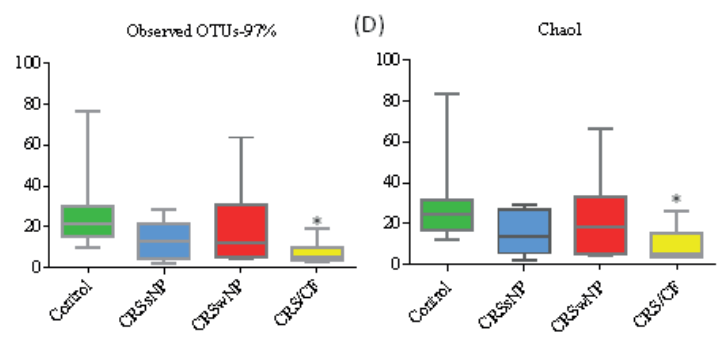

Figure 1. Box and whisker plots comparing bacterial community diversity between CRSwNP, CRSsNP, CRS/CF and healthy control individuals. (A) Shannon-Wiener, (B) Simpson, (C) observed OTUs-97\%, and (D) Chao1 indices were calculated for the four groups of samples. Significant differences ( $p<0.05$, Kruskal-Wallis test) between the CRS/CF and all other groups are displayed on the plots with an asterisk.

Bacterial diversity resembled that previously reported for the human sino-nasal cavity, with considerable variation observed among individuals. Variation based on bacterial community composition between the four groups (CRSsNP, CRSwNP, CRS/CF and control) was measured using a multivariate analysis ('adonis' function in R package). The differences between these four groups explained $11.9 \%$ of the variation in this data set, while the majority of the variation remained unexplained. This indicates that disease status does not play a major role in accounting for the variation observed in bacterial community composition among individuals in this study. Overall, 22 dominating genera were found across all 36 samples, with only one or two dominating in each sample, including members of the genera Pseudomonas, Haemophilus, Enterobacter, and Staphylococcus (Figure 2B). A specific bacterial community or causative bacterial agent of CRS was not observed in this study. However, patients with CRS/CF were generally dominated by members of a single genus (such as Pseudomonas, Staphylococcus or Fusobacterium). Interestingly, the control cohort also harboured the same OTUs or genera as the CRS cohort, but generally had greater bacterial community diversity (Fig. S1). Bray-Curtis MDS plots (Fig. S2) reveal that TLR activated samples tend to cluster together at a broad phylum/class level and at genus level. However, no 
(A)

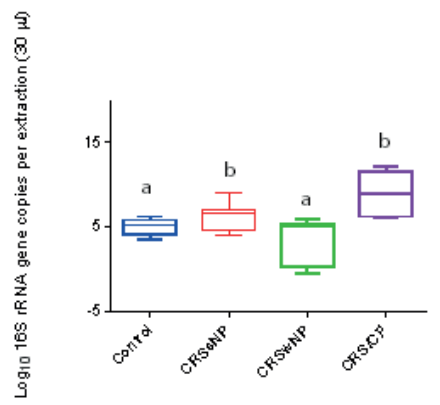

(B)

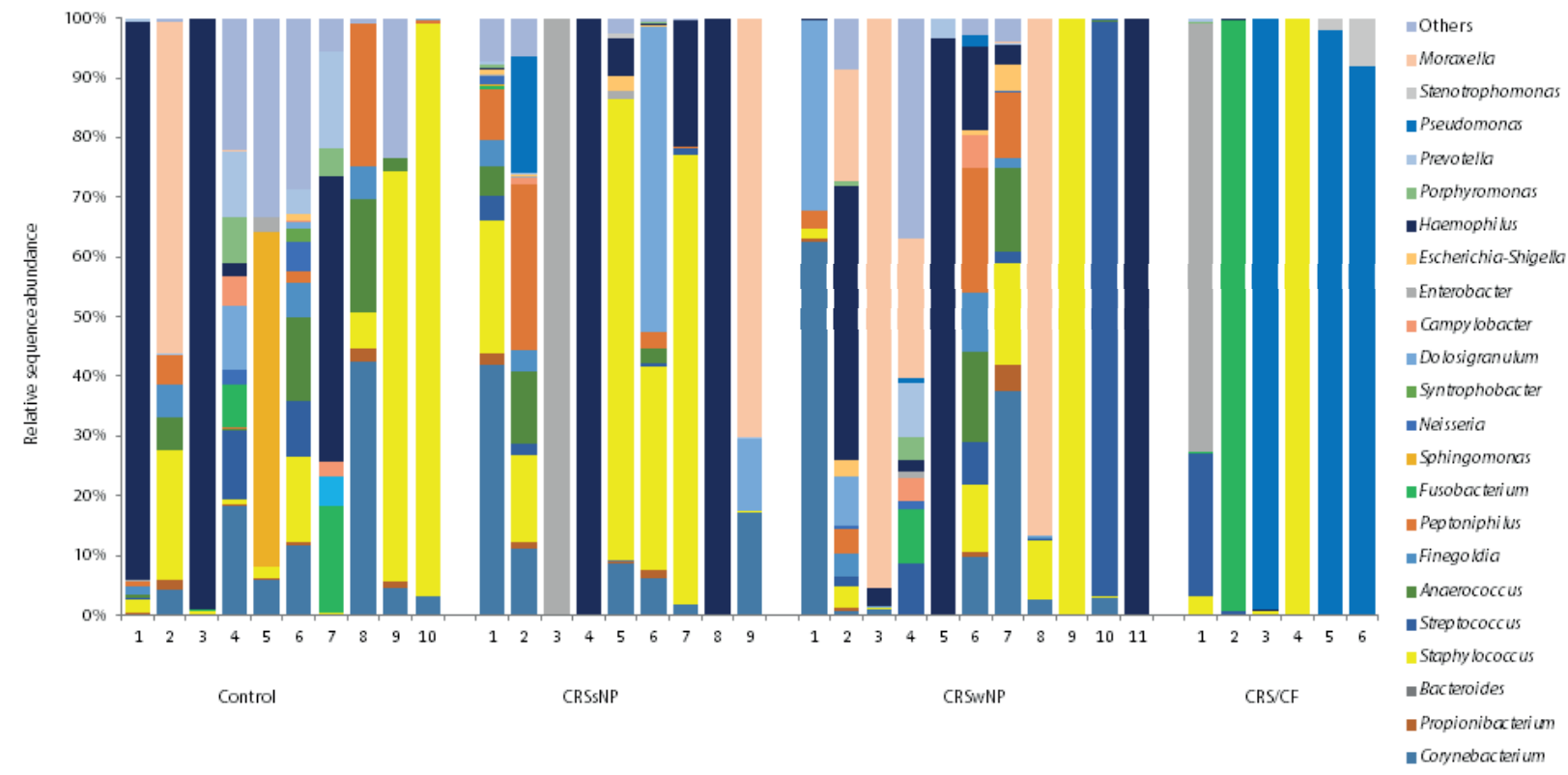

Figure 2. 16S rRNA gene-based bacterial community (A) abundance and (B) composition at genus level in this study. Abundance is displayed as box and whisker plots, which show the median, lower quartile and upper quartile for each sub-group of this study. Bacterial abundance of CRS/CF (b) and CRSsNP (b) groups was significantly higher ( $p<0.05$, Dunn's test with Bonferroni adjustment for multiple comparisons) than CRSwNP (a) and healthy controls (a). 16S rRNA gene copy numbers are used as a proxy for bacterial abundance in qPCR. Bacterial composition, displayed as bar graphs for each individual, are represented as relative sequence abundance.

obvious clusters between the four sub-groups of this study were observed.

Quantitative real-time PCR was used to estimate the bacterial load in each sample (Figure 2A). Patients with CRS/CF had significantly higher ( $p<0.05$, Dunn's test with Bonferroni adjustment for multiple comparisons) bacterial load compared with healthy controls and CRSwNP. Interestingly, the CRSsNP cohort also had a higher bacterial load than CRSwNP and healthy control samples. There were no significant differences in bacterial load between the other groups. Again, as previously mentioned, inter-patient variability within cohorts was substantial and single patients may be accounting for the majority of the changes observed (Figure 2A).

\section{Inflammatory cytokine profiles in nasal mucus}

To determine the type of host inflammatory responses with CRS, inflammatory cytokine markers were measured in the sino-nasal lavage samples (Figure 3). Of the seven measured cytokines, IL-6 and TNF produced the highest signals for healthy controls (Figure 3A), CRSsNP (Figure 3B), CRSwNP (Figure 3C), and CRS/ CF (Figure 3D). Low level measurements of IL-10 and IL-17A were also observed in one or two patients from each cohort. Correlations between patients that produced higher levels of TNF or IL- 6 with disease severity and TLR activation will be explored in a following section.

\section{TLR activation by sino-nasal mucus}

Expression of TLRs in the sino-nasal tissue, together with host mechanisms that preclude engagement with the receptor, will significantly influence the inflammatory response. In this study, TLR activation by sino-nasal mucus was measured in vitro. Similar experimental models have been used previously to measure TLR activation by bacterial pathogens ${ }^{(29,30)}$. Dunnett's test for multiple comparisons was performed to evaluate significant 
(A)

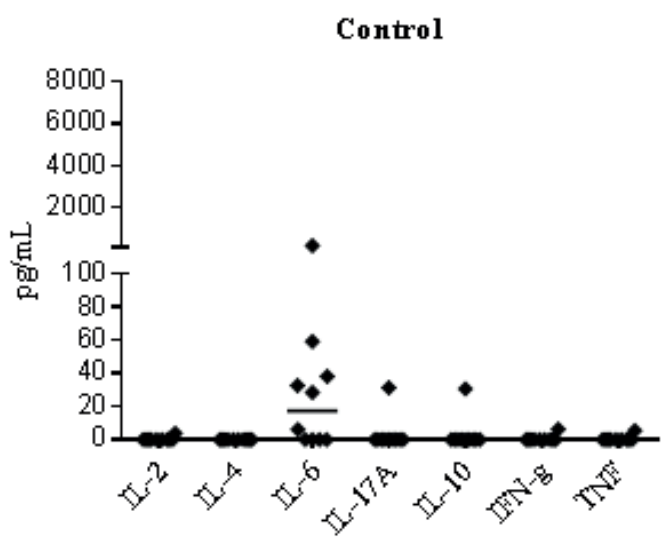

(C)

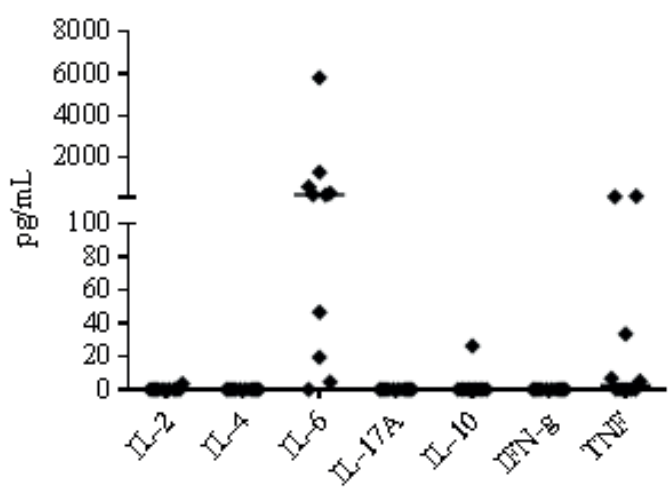

(B)

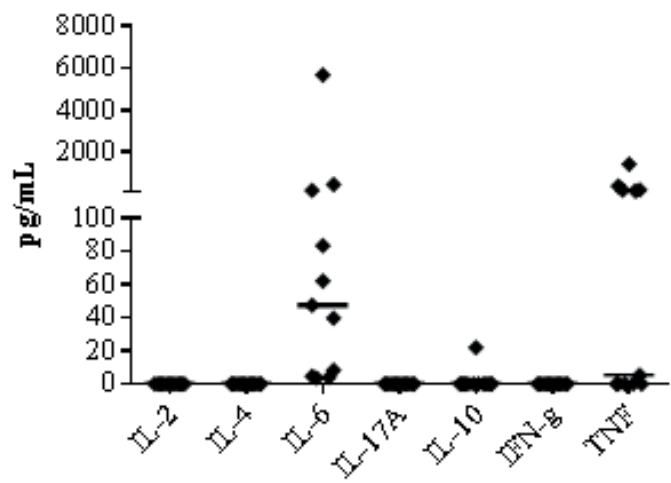

(D)

CRS/CF

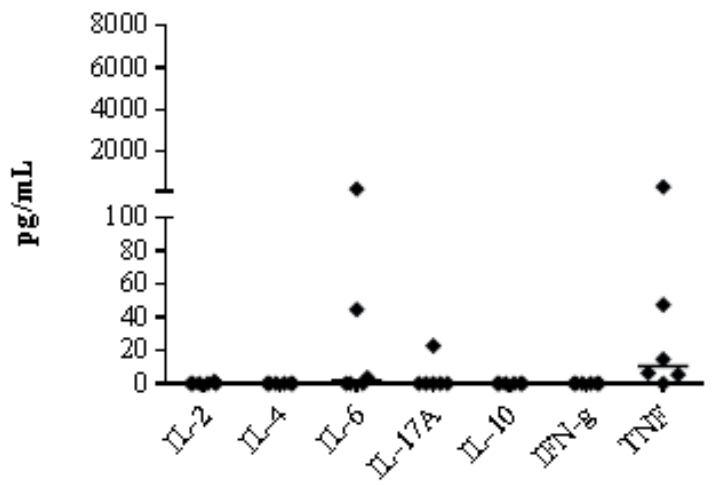

Figure 3. Measurements of pro-inflammatory cytokines IL-2, IL-4, IL-6, IL-17A, IL-10, IFN- $\gamma$, and TNF in the mucus samples of 36 individuals. Patients are split into four groups based on clinical diagnosis: healthy control (A), CRS without nasal polyps (B), CRS with nasal polyps (C), and CRS with cystic fibrosis (D). Horizontal bars represent the median value for each of the measured cytokines.

activation of TLRs compared with a negative control. Activity of TLRs was not consistent across all patients within each group. A small proportion of the patients had either TLR2/1 (CRS/CF-5,6) or TLR4 (Control-3; CRSsNP-8; CRSwNP-5,11) activation and in some cases both of these TLRs (Control-7; CRSsNP-3,4) were activated (Figure 4). The potential microbial triggers of TLR activity for these patients were investigated further.

\section{Correlation between TLR activation and other significant factors}

Of the 26 CRS samples in this study, seven exhibited measurable TLR activity, while two of the 10 healthy control samples also displayed activation. The CRS samples with TLR activation were further broken down into sub-groups where 3 patients without polyps, 2 patients with polyps and 2 with CF displayed activity. There were no measured clinical confounders (such as asthma, antibiotics, or aspirin sensitivity) associated with the patients that were positive for TLR activity. The microbiota of TLR activate samples were largely composed of a single Gram-negative genus belonging to the class Gammaproteobacteria (Figure 5A). In particular, members of the genera Haemophilus, Pseudomonas and Enterobacter dominated ( $>90 \%$ of the sequence reads) the
CRS bacterial community of these TLR activated samples (Figure 5B). Haemophilus also played an important role in the two TLR activated control samples, along with Fusobacteria (20\%) to a lesser extent. Interestingly, the two TLR activated CF/CRS patients behaved slightly differently to other CRS samples in that they were predominantly composed of Pseudomonas and not Haemophilus, and displayed measured activity with only TLR2/1 receptors. Furthermore, Gram-positive organisms (such as Staphylococcus, Corynebacterium, and Streptococcus) were positively correlated with non-TLR activated CRS samples.

Bacterial abundance was elevated in TLR activated compared with non-activated samples within each CRS sub-group (Figure 5C). Interestingly, this difference was not observed in activated versus non-activated TLRs in the healthy cohort. However, the significance of this finding cannot be tested due to the small sample size of TLR activated samples.

TNF and IL-6 were detected in negligible amounts in control samples. In contrast, TLR activated CRS samples correlated positively with TNF, indicative of an elevated host inflammatory response amongst these cohorts (Figure 5D). However, IL-6 did not correlate with the activity of the two measured TLRs in this study. 


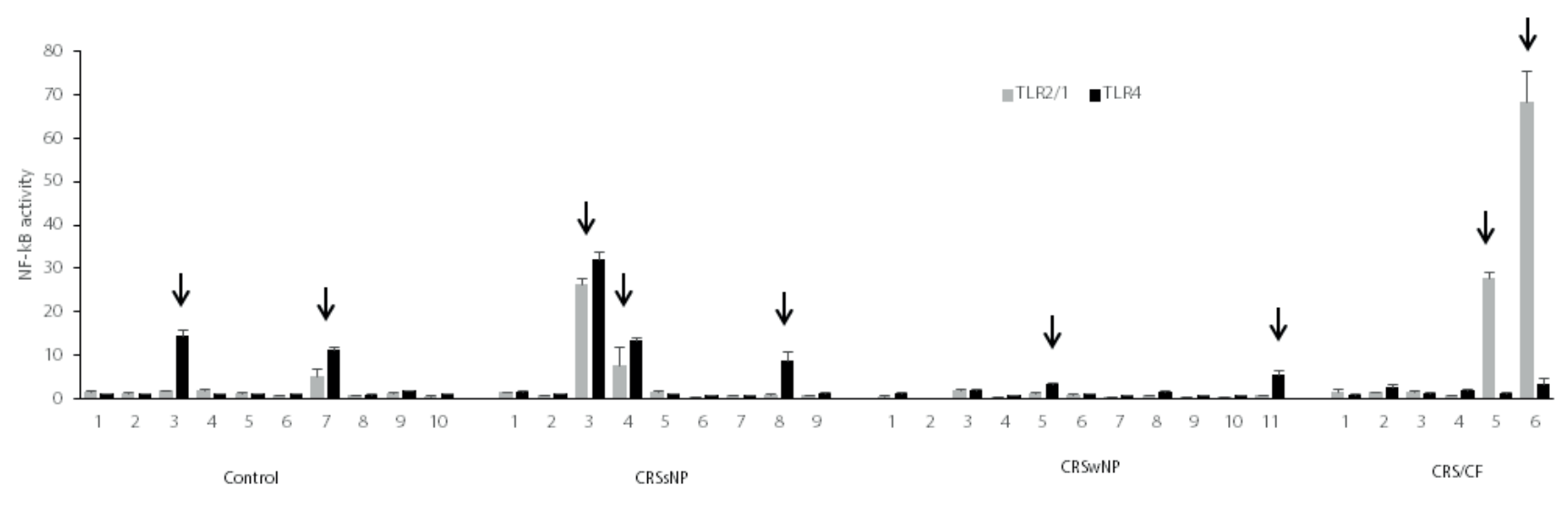

Figure 4. Toll-like receptor stimulation by sino-nasal mucus in vitro was recorded by measuring NF-kB activation. Measurements of NF-kB activity (mean $\pm \mathrm{SE}$ ) were recorded for each individual of this study for the two TLRs (TLR2/1-grey bars and TLR4-black bars) of interest at $50 \mathrm{pg} / \mu \mathrm{L}$ of mucus. Black arrows indicate samples that displayed elevated TLR activity over negative control.

\section{Discussion}

This study of a cohort of 36 individuals is the first to report on significant associations between the sino-nasal microbiota and TLR activation. Twenty-six patients with CRS and 10 healthy controls were chosen. Our results demonstrate that Gram-negative members of the Gammaproteobacteria dominate the bacterial community of both TLR2/1 and TLR4 activated samples. Furthermore, TLR activation in CRS cohorts was significantly associated with bacterial abundance and host release of the pro-inflammatory cytokine TNF. There were no patterns observed between clinical confounders (such as prevalence of asthma, antibiotic and prednisone usage or aspirin sensitivity) and TLR activity within the cohort of this study. However, with larger cohorts it is possible that these associations become more apparent. Mucus contains a range of toxins, tissue injury factors, damage-associated molecular pattern molecules and pathogens including viruses ${ }^{(31)}$. However, by specifically investigating the activation of TLR2/1 and TLR4 receptors, that are stimulated by components of Gram-positive and -negative bacteria, this study focuses on the sino-nasal bacterial interactions with TLR receptors. Patterns of bacterial interactions within the healthy control and diseased groups were observed and will be discussed further below.

\section{TLR activation and host immune response}

The results from the current study show that TLR2/1 and TLR4 were activated by the sino-nasal mucus layer of seven CRS samples, which could have directly influenced the elevated measurements of TNF in the mucus of these samples. In contrast, the two control samples showed no TNF activity. TNF has been suggested to play a synergistic role in the induction of chronic inflammation when in the presence of Th1 or Th2 cytokines (32). IL-6 and TNF have previously been found to be significantly elevated in tissues of CRS patients relative to healthy nasal tissue ${ }^{(33)}$. Furthermore, treatment with corticosteroids reduced symptoms of disease and led to corresponding reduction in IL-6 and TNF, suggesting that these cytokines are correlated with inflammation. The possibility that some of the cytokines investigated in this study were not detected due to the diluted nature of nasal lavages must also be acknowledged.

\section{Bacterial interactions with TLR}

The strong positive correlation between TLR2/1 and TLR4 activity and members of the Gammaproteobacteria (Haemophilus, Enterobacter, Pseudomonas) in the CRS sub-groups, suggests that bacterial composition plays an important role in stimulating TLRs. However, the two control samples that also displayed TLR activity were dominated by Haemophilus but did not show mucosal inflammation. We conclude that other factors along with bacterial composition must be involved in TLR activation and chronic inflammation. Bacterial species richness and evenness (as measured by Shannon-Wiener, Simpson index, observed OTUs and Chao1) could also influence TLR activity, as the results from this study show that samples with TLR activity tend to have lower bacterial diversity than their counterparts. Another possible explanation is that some individuals are more prone to immune hyperresponsiveness to commensal microorganisms, as has been suggested previously ${ }^{(15)}$. Interestingly, organisms commonly implicated in CRS such as members of Staphylococcus, Corynebacterium, Moraxella, were found exclusively in patients without TLR activity in all sub-groups of this study ${ }^{(6,34-36)}$. The association with a negative immune response suggests that it may play a role in downregulation of the host immune response. Evidence of $S$. aureus cells forming microcolonies within the tissue of the sinus mucosa without inducing a local immune reaction has been found previously ${ }^{(37)}$. Suppression of the host immune system may also be due to the constant exposure to microbial components in the mucus layer, resulting in a desensitisation effect ${ }^{(38)}$. 


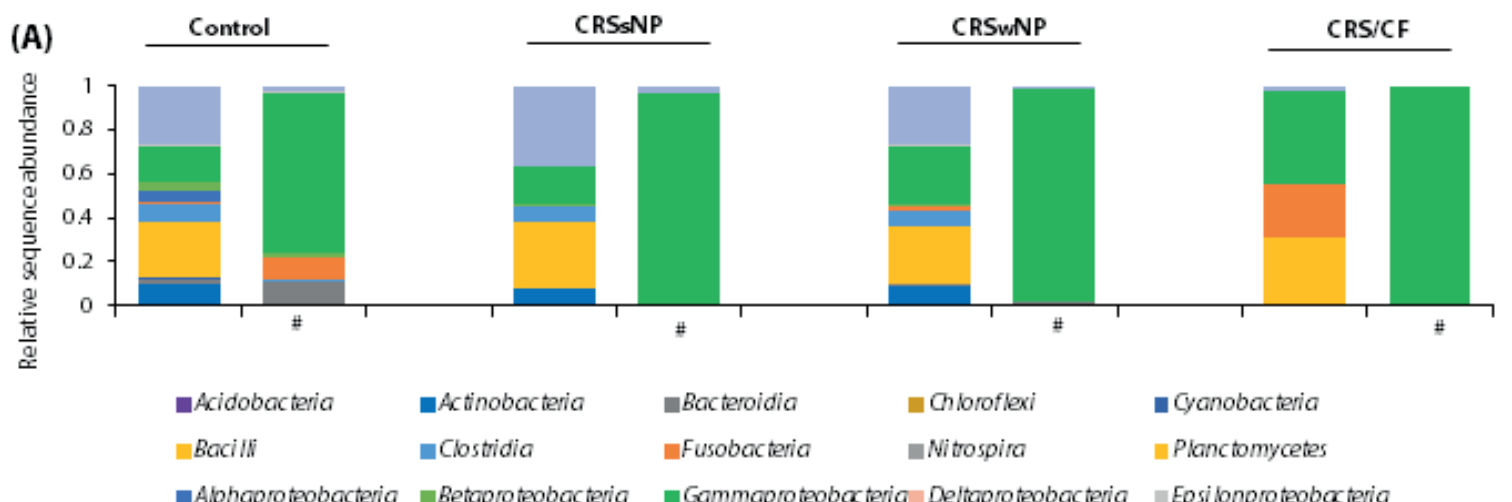

(B)

-Verrucomicrobia =other

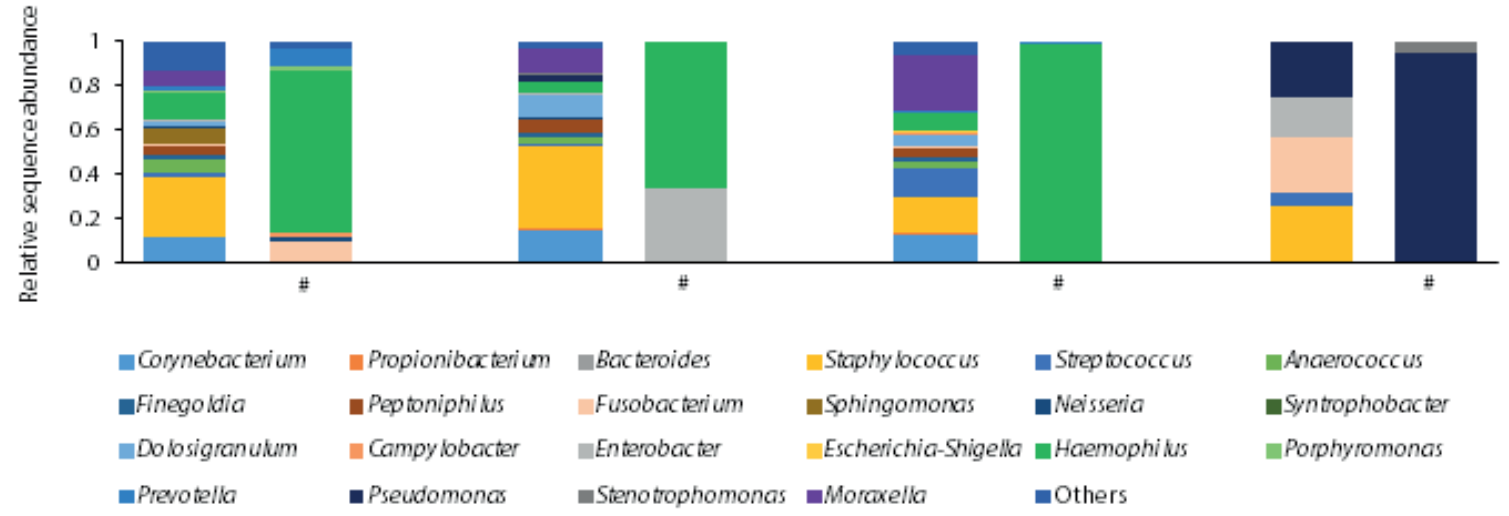

(C)

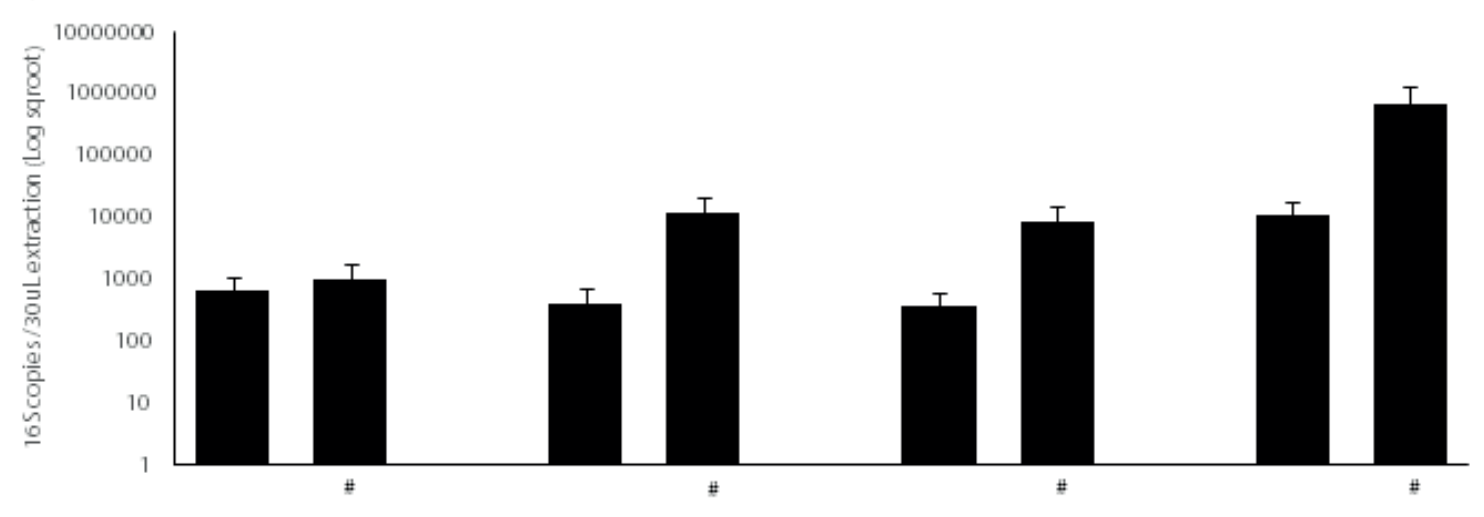

(D)

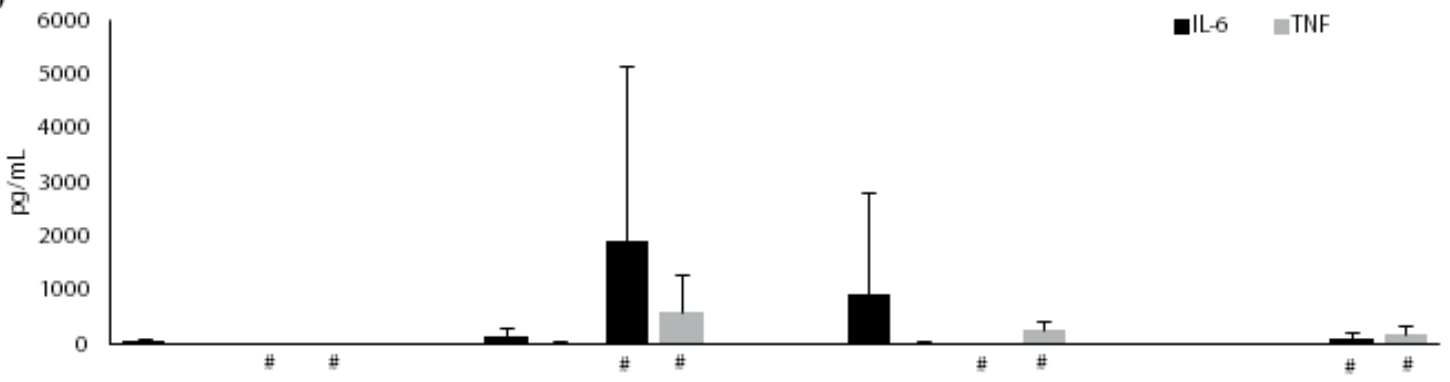

Figure 5. Samples that displayed TLR activity were averaged and displayed as bar graphs within each sub-group of this study. The bacterial community ((A) phylum/class level and (B) genus level), bacterial abundance (C) and cytokine measurements (IL-6 and TNF) (D) were re-evaluated based on these new groupings. The mean and standard deviation is displayed in graphs (C) and (D). \# represents TLR activated groups of samples. 
Bacterial burden in CRS patients plays a major role in TLR activation, as seen in this study. Within the TLR activated cohort, patients with CF have significantly higher bacterial abundance compared with CRSwNP and healthy controls. Several studies suggest that CF involves a defective epithelium or innate immune response due to $\mathrm{CF}$ transmembrane conductance regulator mutations, which lead to impaired mucociliary clearance and accumulation of pathogens ${ }^{\left({ }^{39}\right)}$. The higher abundance of bacteria observed in TLR activated CF patients in this study is probably due to defective mucociliary clearance of the airway epithelial cells, though this requires further investigation. In addition, the antimicrobial therapies used for CF patients could be selecting for organisms that are resilient (Pseudomonas aeruginosa) or resistant (S. aureus) ${ }^{(40,41)}$.

One hypothesis holds that patients with a disrupted epithelial layer have TLRs that are more exposed to pathogens in the mucus layer, which then initiates the immune response and inflammation ${ }^{(7)}$. Disruption of the epithelial barrier has been observed previously among patients with asthma and CRS ${ }^{(42,}$ ${ }^{43}$. In this study, we speculate that some patients with CRS are predisposed to TLR activation due to compromised integrity of the epithelial barrier, which then leads to a heightened immune response, resulting in inflammation. However, this requires further investigation.

\section{Conclusion}

In conclusion, the results of this study open a new perspective on CRS and possible microbial instigators of inflammation in this disease. We speculate that chronic inflammation in the sinuses is caused by multiple pathways and factors between the host and the environment, however by better understanding one such pathway (through TLRs), the complexities of such a disease can begin to be unravelled. Results from this preliminary study suggest that only a small proportion (20-30\%) of patients from each subgroup display measurable TLR activity. Future studies would greatly benefit from larger cohorts to help solidify the positive correlations found between bacterial composition, bacterial abundance, TNF and TLR activity. In addition, future research in this area should focus on investigating TLR activation by clinical bacterial isolates of CRS patients, which will help strengthen the findings of this study.

\section{Acknowledgement}

The authors would like to thank the individuals who took part in this study. The research reported here was funded by Medtronic Xomed, Inc. The authors would especially like to thank Bo Lewis who helped secure funding for this study. We would also like to thank Brett Wagner and Dave Waite for their help with the development of the bioinformatics pipeline for the processing of the raw 165 rRNA gene sequence data.

\section{Authorship contribution}

Conceived, study design and collection: K.B., R.D., R.G.D.

Performed the experiments: K.B., A.C., M.H., F.J.R.

Analysis and interpretation: K.B., F.J.R., Y.J.

Writing the report: K.B., F.J.R, Y.J., M.W.T., R.D.

Critical review of the paper: All authors

\section{Conflict of interest}

The authors declare no conflict of interest relevant to this study.

\section{References}

1. Bhattacharyya N. The economic burden and symptom manifestations of chronic rhinosinusitis. Am J Rhinol 2003; 17:27-32.

2. Fokkens WJ, Lund VJ, Mullol J, et al. EPOS 2012: European position paper on rhinosinusitis and nasal polyps 2012. A summary for otorhinolaryngologists. Rhinology 2012; 50:1-12.

3. Park SJ, Kim TH, Jun YJ, et al. Chronic rhinosinusitis with polyps and without polyps is associated with increased expression of suppressors of cytokine signaling 1 and 3 . J Allergy Clin Immunol 2013; 131:772-780.

4. Bachert C, Zhang N, Van Zele T, and Gevaert P. Chronic rhinosinusitis: From one disease to different phenotypes. Pediatr Allergy Immunol 2012; 23:2-4.

5. Lam K, Schleimer R, and Kern RC. The etiology and pathogenesis of chronic rhinosinusitis: a review of current hypotheses. Curr Allergy Asthma 2015; 15:1-10.

6. Biswas K, Hoggard M, Jain R, Taylor MW, and Douglas RG. The nasal microbiota in health and disease: variation within and between subjects. Front Microbiol 2015; 9:134.

7. Tieu DD, Kern RC, and Schleimer RP. Alterations in epithelial barrier function and host defense responses in chronic rhinosinusitis. J Allergy Clin Immunol 2009; 124:3742.

8. Pothoven $\mathrm{KL}$, Norton JE, Hulse $\mathrm{KE}$, et al Oncostatin M promotes mucosal epithelial barrier dysfunction, and its expression is increased in patients with eosinophilic mucosal disease. J Allergy Clinical Immunol 2015

9. Ramanathan M, and Lane AP. Innate immunity of the sinonasal cavity and its role in chronic rhinosinusitis. Otolaryngol Head Neck Surg 2007; 136:348-356.

10. VanderMeer J, Sha Q, Lane AP, and Schleimer RP. Innate immunity of the sinonasal cavity: expression of messenger RNA for complement cascade components and toll-like receptors. Arch Otolaryngol Head Neck Surg 2004; 130:1374-1380.

11. Sha $Q$, Truong-Tran $A Q$, Plitt JR, Beck $L A$, and Schleimer RP. Activation of airway epithelial cells by toll-like receptor agonists. Am J
Respir Cell Mol Biol 2004; 31:358-364.

12. Kawai $T$, and Akira S. The role of patternrecognition receptors in innate immunity: update on Toll-like receptors. Nature Immunol 2010; 11:373-384.

13. Dong Z, Yang Z, and Wang C. Expression of TLR2 and TLR4 messenger RNA in the epithelial cells of the nasal airway. Am J Rhinol 2005; 19:236-239.

14. Sun $Y$, Zhou B, Wang $C$, et al. Biofilm formation and Toll-like receptor 2, Toll-like receptor 4, and NF-kappaB expression in sinus tissues of patients with chronic rhinosinusitis. Am J Rhinol Allergy 2012; 26:104-109.

15. Aurora R, Chatterjee D, Hentzleman J, Prasad $G$, Sindwani $R$, and Sanford $T$. Contrasting the microbiomes from healthy volunteers and patients with chronic rhinosinusitis. JAMA Otolaryngol Head Neck Surg 2013; 139:1328-1338.

16. Chalermwatanachai T, Zhang N, Holtappels $G$, and Bachert C. Association of Mucosal Organisms with Patterns of Inflammation in Chronic Rhinosinusitis. PloS one 2015; 10:e0136068. 
17. Herlemann DP, Labrenz $M$, Jürgens $K$ Bertilsson S, Waniek JJ, and Andersson AF. Transitions in bacterial communities along the $2000 \mathrm{~km}$ salinity gradient of the Baltic Sea. ISME J 2011; 5:1571-1579.

18. Klindworth A, Pruesse $E$, Schweer $T$, et al Evaluation of general $16 \mathrm{~S}$ ribosomal RNA gene PCR primers for classical and nextgeneration sequencing-based diversity studies. Nucl Acid Res 2012:gks808.

19. Cole JR, Chai B, Farris RJ, et al. The Ribosomal Database Project (RDP-II) sequences and tools for high-throughput rRNA analysis. Nucl Acid Res 2005; 33:D294-D296.

20. Caporaso JG, Kuczynski J, Stombaugh J, et al. QIIME allows analysis of high-throughput community sequencing data. Nat Methods 2010; 7:335-336.

21. Edgar RC. UPARSE: highly accurate OTU sequences from microbial amplicon reads. Nat Methods 2013; 10:996-998.

22. Price MN, Dehal PS, and Arkin AP. FastTree 2-approximately maximum-likelihood trees for large alignments. PloS one 2010; 5:e9490.

23. Wang $X$, and Seed B. A PCR primer bank for quantitative gene expression analysis. Nucl Acids Res 2003; 31:e154-e154

24. Kim YM, Ahn CK, Woo SH, Jung GY, and Park JM. Synergic degradation of phenanthrene by consortia of newly isolated bacteria strains. J Biotechnol 2009; 144:293-298.

25. Juck D, Charles T, Whyte L, and Greer C. Polyphasic microbial community analysis of petroleum hydrocarbon-contaminated soils from two northern Canadian communities. FEMS Microbiol Ecol 2000; 33:241-249.

26. Oyer SL, Mulligan JK, Psaltis AJ, Henriquez OA, and Schlosser RJ. Cytokine correlation between sinus tissue and nasal secretions among chronic rhinosinusitis and controls. Laryngoscope 2013; 123:E72-E78.

27. Hentschel J, Jäger $M$, Beiersdorf $N$, et al. Dynamics of soluble and cellular inflammatory markers in nasal lavage obtained from Cystic Fibrosis patients during intravenous antibiotic treatment. BMC Pulm Med 2014; $14: 82$.
28. Coats SR, Reife RA, Bainbridge BW, Pham T-TT, and Darveau RP. Porphyromonas gingivalis lipopolysaccharide antagonizes Escherichia coli lipopolysaccharide at tolllike receptor 4 in human endothelial cells. Infect Immun 2003; 71:6799-6807.

29. Chow JC, Young DW, Golenbock DT, Christ WJ, and Gusovsky F. Toll-like receptor-4 mediates lipopolysaccharide-induced signal transduction. J Biol Chem 1999; 274:10689-10692.

30. Jain S, Coats SR, Chang AM, and Darveau RP. A novel class of lipoprotein lipase-sensitive molecules mediates Toll-like receptor 2 activation by Porphyromonas gingivalis. Infection and immunity 2013; 81:1277-1286.

31. Thornton DJ, Rousseau K, and McGuckin MA. Structure and function of the polymeric mucins in airways mucus. Annu Rev Physiol 2008; 70:459-486.

32. Otto BA, and Wenzel SE. The role of cytokines in chronic rhinosinusitis with nasal polyps. Curr Opin Otolaryngol Head Neck Surg 2008; 16:270-274.

33. Lennard CM, Mann EA, Sun LL, Chang AS, and Bolger WE. Interleukin-1 beta, Interleukin-5, Interleukin-6, Interleukin-8, and Tumor Necrosis Factor-a in chronic sinusitis: response to systemic corticosteroids. Am J Rhinol 2000; 14:367-373.

34. Foreman A, Holtappels G, Psaltis A et al. Adaptive immune responses in Staphylococcus aureus biofilm-associated chronic rhinosinusitis. Allergy 2011; 66:1449-1456.

35. Feazel LM, Robertson CE, Ramakrishnan VR and Frank DN. Microbiome complexity and Staphylococcus aureus in chronic rhinosinusitis. Laryngoscope 2012; 122:467-472.

36. Abreu NA, Nagalingam NA, Song $Y$, et al. Sinus microbiome diversity depletion and Corynebacterium tuberculostearicum enrichment mediates rhinosinusitis. Sci Transl Med 2012; 4:151ra124-151ra124.

37. Wood AJ, Fraser JD, Swift S, PattersonEmanuelson EA, Amirapu S, and Douglas RG. Intramucosal bacterial microcolonies exist in chronic rhinosinusitis without inducing a local immune response. Am J
Rhinol Allergy 2012; 26:265-270.

38. Didierlaurent A, Goulding J, Patel S, et al. Sustained desensitization to bacterial Tolllike receptor ligands after resolution of respiratory influenza infection. J Exp Med 2008; 205:323-329.

39. Cohen TS, and Prince A. Cystic fibrosis: a mucosal immunodeficiency syndrome. Nat Med 2012; 18:509-519.

40. Dasenbrook EC, Checkley W, Merlo CA, Konstan MW, Lechtzin N, and Boyle MP. Association between respiratory tract methicillin-resistant Staphylococcus aureus and survival in cystic fibrosis. JAMA 2010; 303:2386-2392.

41. Bomberger JM, Ye S, MacEachran DP, et al. A Pseudomonas aeruginosa toxin that hijacks the host ubiquitin proteolytic system. PLoS Pathog 2011; 7:e1001325.

42. Xiao C, Puddicombe SM, Field S, et al. Defective epithelial barrier function in asthma. J Allergy Clin Immunol 2011; 128:549556. e512.

43. Steelant B, Farré R, Wawrzyniak $P$, et al. Impaired barrier function in patients with house dust mite-induced allergic rhinitis is accompanied by decreased occludin and zonula occludens-1 expression. J Allergy Clin Immunol 2016; 137:1043-1053. e1045.

\section{Richard G. Douglas \\ Associate professor \\ Department of Surgery, Level 12, \\ Auckland City Hospital \\ Park Road, Grafton \\ Auckland 1023 \\ New Zealand}

Tel: + 64272186083

Fax: +64 3779656

E-mail:

richard.douglas@auckland.ac.nz 